\title{
ANALISIS PENGARUH MODEL AISAS (ATTENTION, INTEREST, SEARCH, ACTION \& SHARE) TERHADAP TINGKAT LITERASI KEUANGAN SYARIAH (STUDI KASUS FOLLOWERS INSTAGRAM PERBANKAN SYARIAH)
}

\author{
Joni Iskandar \\ Program Pascasarjana Magister Ekonomi Syariah, Institut Agama Islam Tazkia, Bogor \\ Email: joniskan076@gmail.com \\ Mukhamad Najib \\ Departemen Manajemen, IPB University \\ Email: najib@apps.ipb.ac.id \\ Ahmad Mukhlis Yusuf \\ Program Pascasarjana Magister Ekonomi Syariah, Institut Agama Islam Tazkia, Bogor \\ Email: amukhlisyusuf@gmail.com
}

\begin{abstract}
The Financial Services Authority (OJK) states that one of the root causes of the slow growth in the market share of Islamic banking is due to the weak literacy of Indonesian people towards sharia finance. Based on a 2016 National Literacy and Financial Inclusion survey involving 9,680 research respondents from 34 provinces in 64 cities / districts. shows that the national Islamic financial literacy rate is 8.11 percent. While on the other hand, there has been an increase in internet usage among Indonesian people. The research aims to find out how the AISAS model which consists of Attention, Interest, Search, Action and Share affects the level of literacy of Islamic banking in followers of Islamic banking in Indonesia. Research consists of three stages namely literature study. Then a field study was conducted by distributing questionnaires to 183 respondents. The analysis method used is Structural Equation Modeling (SEM) using AMOS software. The results show that (1) Attention variable has a significant and positive effect on the dependent variable, namely interest. (2) Interest variables have a significant and positive effect on the dependent variable, namely search. (3) The search variable has a significant and positive effect on the dependent variable, namely action. (4) The action variable has a significant and positive effect on the dependent variable, which is share. (5) The search variable has a significant and positive effect on the dependent variable, namely Sharia Banking Literacy. (6) The action variable has a significant and positive effect on the dependent variable, namely Sharia Banking Literacy. (7) The share variable does not have a significant effect even though it has a positive value on the dependent variable, namely Sharia Banking Literacy.
\end{abstract}

Keywords: Instagram, AISAS Model, Literacy and Islamic Banking Literacy. 


\section{Dasar Pemikiran}

Ekonomi merupakan dimensi yang tidak bisa dipisahkan dengan kehidupan umat manusia. Pembahasan mengenai ekonomi sama tuanya dengan kehidupan manusia itu sendiri. Salah satu komponen terpenting dalam pembahasan ekonomi di abad modern adalah perbankan. Lembaga yang menjadi intermediasi dalam pengelolaan dana sekaligus mengambil peran penting dalam mendorong pertumbuhan ekonomi masyarakat dalam sebuah negara. Tak bisa dipungkiri jika denyut nadi pembangunan sebuah negara tidak akan terlepas dari perbankan. Lembaga keuangan seperti bank mempunyai peran strategis bagi aktivitas prekonomian. Peran penting bank tersebut sebagai wahana yang mampu menghimpun dana masyarakat secara efektif dan efisien ke arah peningkatan taraf hidup masyarakat. Bank menjadi entitas penting untuk menjunjung kelancaran perekonomian (Wiwoho, 2014).

Sejalan dengan penjelasan yang tertuang dalam Undang-Undang nomor 10 tahun 1998 bahwa bank merupakan badan usaha yang menghimpun dana dari masyarakat dalam bentuk simpanan dan menyalurkannya kembali kepada masyarakat dalam bentuk kredit. Bisa dikatakan perbankan memiliki peran yang tak terpisahkan dengan kehidupan masyarakat. Namun sistem perbankan pada umumnya yanag ada di Indonesia atau biasa dikenal dengan perbankan konvensional masih mengandung riba, dan riba hukumnya haram menurut syariat agama Islam (Antonio, 2001).

Adapun perbankan syariah yang hadir di tengah-tengah perbankan konvesional seperti jawaban dari kegelisahan umat sekaligus menjadi alternatif bagi kebutuhan transaksi keuangan umat Islam agar terhindar dari jebakan riba. Ada dua alasan utama mengenai latar belakang berdirinya bank syariah, yaitu: (1) adanya pandangan bahwa bunga (interest) pada bank konvensional itu hukumnya haram karena termasuk dalam kategori riba yang dilarang dalam agama, bukan saja pada agama Islam tetapi juga oleh agama samawi lainnya; (2) dari aspek ekonomi, penyerahan resiko usaha terhadap salah satu pihak dinilai melanggar norma keadilan dan dapat menimbulkan rasa mementingkan diri sendiri (selfishness) (Rahmawaty, Anita: 2014) 
Pertumbuhan perbankan syariah di Indonesia terus meningkat dari waktu ke waktu sekalipun masih belum sesuai dengan harapan. Berdasarkan data yang dihimpun oleh Otoritas Jasa Keuangan (OJK) pada bulan Desember 2018, setidaknya sudah berdiri 14 Bank UmumSyariah (BUS), 20 Unit Usaha Syariah (UUS) dan 165 Bank Pembiayaan Rakyat Syariah (BPRS) dengan nilai kapitalisasi aset produktif gabungan antara BUS dan UUS mencapai Rp. 466.800 Milyar.

Tabel Pertumbuhan Perbankan Syariah

\begin{tabular}{|l|c|c|c|c|c|c|c|c|}
\hline Indikator & $\mathbf{2 0 1 1}$ & $\mathbf{2 0 1 2}$ & $\mathbf{2 0 1 3}$ & $\mathbf{2 0 1 4}$ & $\mathbf{2 0 1 5}$ & $\mathbf{2 0 1 6}$ & $\mathbf{2 0 1 7}$ & $\mathbf{2 0 1 8}$ \\
\hline Bank Umum Syariah \\
\hline Jumlah Bank & 11 & 11 & 11 & 12 & 12 & 13 & 13 & 14 \\
\hline Jumlah Kantor & 1.401 & 1.745 & 1.998 & $\begin{array}{c}2.15 \\
1\end{array}$ & 2.121 & 1869 & 1.825 & 1.875 \\
\hline Unit Usaha Syariah & & & & & \\
\hline Jumlah USUS & 24 & 24 & 23 & 22 & 22 & 21 & 21 & 20 \\
\hline Jumlah Kantor & 336 & 517 & 590 & 320 & 327 & 332 & 344 & 354 \\
\hline BPR Syariah & 155 & 158 & 163 & 163 & 161 & 166 & 167 & 167 \\
\hline Jumlah Bank & 364 & 401 & 402 & 439 & 433 & 453 & 441 & 495 \\
\hline Jumlah Kantor
\end{tabular}

Sumber: Statistik Perbankan Syariah, Januari 2019

Jika dilihat dari awal berdirinya bank syariah pertama di Indonesia, pertumbuhannya cukup mengesankan. Namun meski kinerja perbankan syariah dinilai baik, jika dibandingkan dengan perbankan konvensional, aset dan pangsa pasar perbankan syariah di Indonesia berdasarkan data terakhir sampai kurun waktu Desember 2016 hanya mampu menembus angka 5,3\%. Perbandingan pertumbuhan aset dan pangsa pasar perbankan di Indonesia bisa dilihat pada tabel dibawah ini;

Tabel Pertumbuhan Pangsa Pasar Perbankan Syariah

\begin{tabular}{|c|c|c|c|}
\hline Tahun & $\begin{array}{c}\text { Aset Perbankan } \\
\text { Nasional }\end{array}$ & $\begin{array}{c}\text { Aset BUS- } \\
\text { UUS }\end{array}$ & $\begin{array}{c}\text { Market Share } \\
\text { Perbankan Syariah }\end{array}$ \\
\hline 2011 & 3.652 .832 & 145.467 & $3,98 \%$ \\
\hline 2012 & 4.954 .467 & 195.018 & $3,94 \%$ \\
\hline 2013 & 5.615 .150 & 242.276 & $4,31 \%$ \\
\hline 2014 & 5.615 .150 & 272.343 & $4,85 \%$ \\
\hline 2015 & 6.132 .583 & 296.262 & $4,83 \%$ \\
\hline
\end{tabular}

P-ISSN : 2460-9595

DOI: https://doi.org/10.36908/isbank.v5i2.114

E-ISSN : 2686-5149 
36 | Joni Iskandar, Mukhammad Najib, Ahmad Mukhlis Yusuf, ANALISIS PENGARUH MODEL AISAS...

\begin{tabular}{|l|l|l|l|}
\hline 2016 & 6.843 .300 & 356.504 & $5,21 \%$ \\
\hline 2017 & 7.513 .579 & 424.181 & $5,65 \%$ \\
\hline 2018 & 8.204 .039 & 466.800 & $5,69 \%$ \\
\hline
\end{tabular}

Sumber: SPI \& SPS Januari 2019, Diolah.

Padahal jika kita melihat target pangsa pasar perbankan syariah yang dicanangkan Bank Indonesia melalui Cetak Biru Pengembangan Perbankan Syariah di Indonesia yang diterbitkan tahun 2002, target pangsa pasar sebesar 5 persen seharusnya sudah tercapai pada tahun 2011 silam. Bahkan pada tahun 2012 Bank Indonesia (BI) melalui Deputi BI, Halim Alamsyah optimis mampu mencapai pangsa pasar perbankan syariah terhadap industri adri segi aset bisa meningkat menjadi 10 persen. Kenyataanya, di tahun 2018 perbankan syariah baru mampu menyentuh angka 5 persen pangsa pasar industri perbankan nasional

Kekhawatiran pangsa pasar yang baru menembus angka 5 persen menjadi pembahasan semua kalangan baik regulator, praktisi, pemerhati, peneliti maupun akademisi perbankan syariah yang menyatakan bahwa keberhasilan tidak diimbangi dengan market share industri perbankan syariah (Rahman, 2016). Artinya, pasti terdapat permasalahan krusial yang menjadi latar belakang lambatnya pertumbuhan pangsa pasar perbankan syariah. Kegagalan perbankan syariah mencapai target pagsa pasar yang telah dicanangkan oleh Bank Indonesia tentu harus dievalusi dan dicarikan jalan keluarnya.

Otoritas Jasa Keuangan (OJK) menyebutkan bahwa salah satu akar persoalan lambatnya pertumbuhan pangsa pasar perbankan syariah disebabkan karena lemahnya literasi masyarakat Indonesia terhadap keuangan syariah. Berdasarkan survei Nasional Literasi dan Inklusi Keuangan 2016 yang dilakukan oleh OJK dengan melibatkan 9.680 responden penelitian dari 34 Provinsi yang tersebar di 64 kota/kabupaten. Hasilnya menunjukkan bahwa tingkat literasi keuangan syariah nasional 8,11 persen. Hal ini menunjukkan hanya ada 8 orang saja dari 100 penduduk Indonesia yang memiliki pengetahuan, keterampilan dan keyakinan terhadap sektor jasa keuangan syariah. 
Pemahaman masyarakat terhadap produk dan layanan keuangan syariah masih rendah (Sumber: OJK, 2017).

Kendala yang dihadapi oleh masyarakat pada umumnya untuk mengakses sektor jasa keuangan syariah adalah karena kurangnya pengetahuan dan informasi (literasi), serta tidak tersedianya produk atau layanan jasa keuangan yang sesuai dengan kebutuhan dan kemampuan (Sumber: Siaran Pers OJK, 2015). Padahal tingkat pengetahuan masyarakat terhadap keuangan syariah mempengaruhi keputusan untuk untuk menggunakan jasa perbankan syariah. Hal senada juga turut dikonfirmasi penelitian yang dilakukan oleh Sholeh dan Rahmawati yang dipublikasikan pada Jurnal Economia tahun 2018. Tingkat literasi keuangan syariah berpengaruh positif terhadap pengambilan keputusan masyarakat muslim menggunakan produk perbankan syariah. Sehingga literasi keuangan syariah menjadi pokok pembahasan penting dalam mendorong pertumbuhan pangsa pasar perbankan syariah. Selaku penggiat ekonomi syariah, tentu semua elemen yang terakit harus senantiasa mencari cara agar proses sosialisasi dan edukasi keuangan syariah makin masif di kalangan masyarakat. Salah satu cara yang bisa dicoba yakni maksimalisasi penggunaan internet dengan semua instrument turunannya.

Menurut Akinola (2015) internet merupakan media komunikasi pemasaran dan periklanan yang modern. Masyarakat dunia sudah mulai familiar dengan penggunaan internet untuk menunjang aktivitas sehari-hari. Sedangkan menurut Charisma (2014) saat ini masyarakat tidak hanya menggunakan internet untuk berinteraksi dengan orang lain, namun juga menggunakannya sebagai sebuah sarana sosialisasi, membentuk hubungan yang lebih bertahan lama, bahkan malah dapat berkembang secara nyata di dalam kehidupan sosial. Tidak hanya dengan menggunakan komputer/laptop saja tetapi masyarakat juga dapat mengaksesnya melalui handphone dengan berbagai kemudahan yang ditawarkan oleh sejumlah provider telepon selular.

Hasil survei Asosiasi Penyelenggara Jasa Internet Indonesia (APJII) bekerja sama dengan Lembaga Survey Polling Indonesia pada tahun 2018 melaporkan bahwa terdapat 264,16 juta penduduk Indonesia adalah pengguna internet, yakni 64,8 persen dari 171,17 juta jiwa total penduduk Indonesia. 


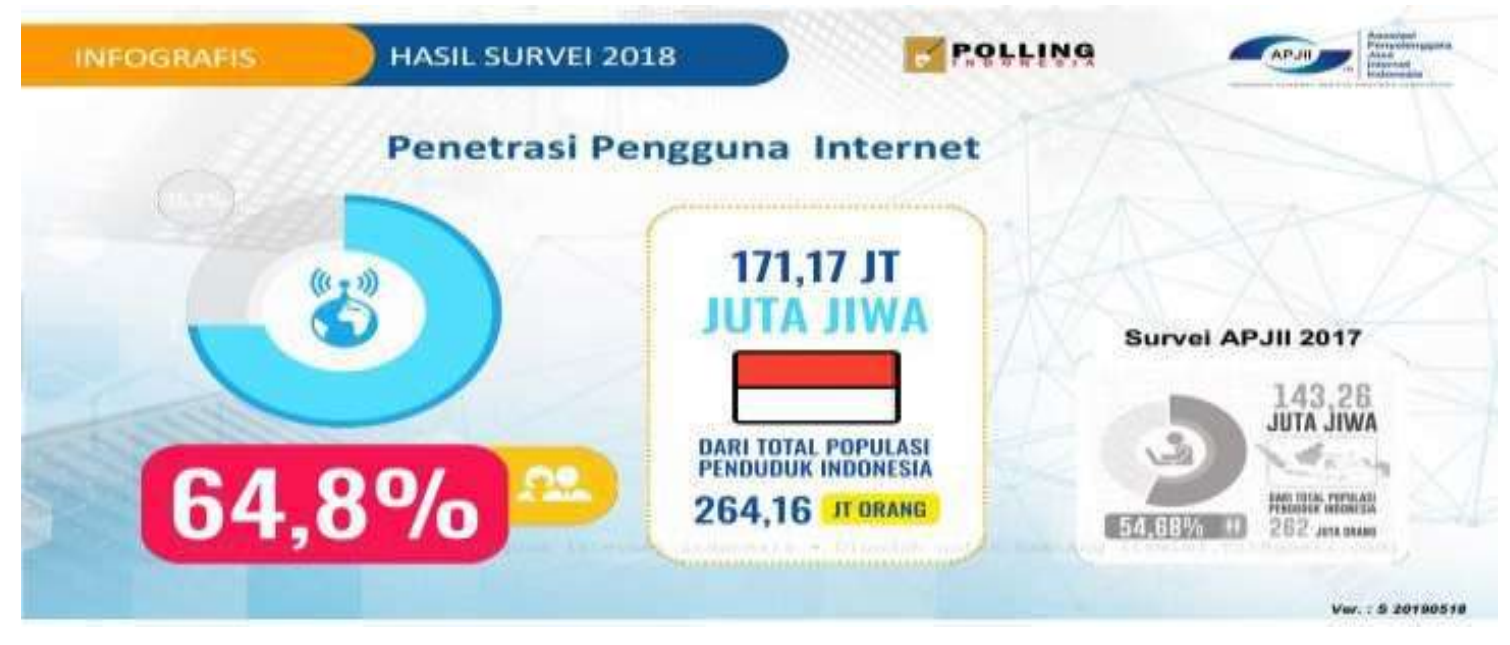

Gambar Pengguna Internet Indonesia

Sumber: Survei APJII tentang Perilaku Pengguna Internet Indonesia, 2018.

Dari data di atas bisa disimpulkan bahwa masyarakat Indonesia sebagian besarnya adalah pengguna internet. Dalam penelitian yang sama diketahui bahwa 19,6 persen pengguna internet menghabiskan waktu selama 8 jam perhari, sebanyak 14,1 persen mengabiskan 3- 4 jam perhari, sebanyak 13,4 persen menghabiskan waktu selama 2-3 jam perhari. Artinya internet dan sarana digital di Indonesia memiliki peluang yang sangat besar untuk dijadikan sebagai sarana untuk mendorong minat baca dan mendongkrak literasi masyarakat terhadap keuangan syariah. Tidak heran jika kemudian bank syariah di Indonesia juga turut menjadikan internet sebagai medium edukasi dan promosi bagi produk-produk perbankan syariah di tanah air.

\section{Tinjauan Pustaka}

\section{Media Sosial Instagram}

Instagram merupakan salah satu media sosial yang paling banyak digunakan saat ini. Adapun pengertian instagram Menurut Jubilee (2012) adalah situs daring yang biasa digunakan untuk saling berbagi foto antara antar sesama pengguna platform di seluruh dunia. Instagram menyerupai galeri foto berukuran raksasa. Setiap orang bisa melihat hasil karya jepretan pengguna instagram yang lain serta juga bias dijadikan media untuk 
saling berjeraring layaknya pertemanan. Secara sederhana, instagram bisa juga dipahami platform digital untuk memotret, mengedit dan menyebar foto yang diunggah ke instgram.

Sedangkan Hardianti (2019) menyampaikan bahwa instagram berasal dari kata "instan" atau "insta" dan "gram" yang bermula dari kata telegram. Instagram merupakan aplikasi sosial media yang bisa digunakan untuk menampilkan foto-foto hasil karya pengguna. Selain itu dalam tampilannya menggunakan jaringan internet agar informasinya dapat disampaikan dengan cepat. Instagram memiliki fungsi yang hampir sama dengan twitter, namun perbedaan keduanya terletak pada pengambilan foto dalam bentuk atau tempat untuk berbagi informasi terhadap pengguna yang lain. Instagram dapat memberikan inspirasi bagi penggunanya dalam meningkatkan kreativitas, karena instagram mempunyai fitur yang dapat membuat foto menjadi lebih indah, lebih artistik dan lebih bagus.

Adapun instagram berdasarkan pengertian yang disampaian oleh Willya et al (2018) ialah media yang memungkinkan penggunanya untuk dapat berbagi cerita dan pengalaman melalui foto disertai caption atau keterangan yang beragam dan sesusia dengan keinginan si pemilik akun instagram. Lazimnya seperti media sosial yang lain, postingan di instagram juga memiliki potensi untuk tersebar dengan cepat dan dapat dilihat oleh berbagai masyarakat lintas lokasi. Sederhannya instagram adalah aplikasi media online untuk berbagi foto yang dapat dilihat oleh follower sekaligus memberikan komentar.

\section{Model AISAS (Attention, Interest, Search, Action, Share)}

Seiring perkembangan zaman, lamban laun juga mempengaruhi perilaku manusia abad modern, terutama dengan kehadiran teknologi internet saat ini. Seorang pengguna jasa bisa lebih leluasa menemukan informasi mengenai produk atau layanan jasa yang hendak digunakan. Hal tersebut secara tidak langsung membuat aktivitas mereka lebih variatif dalam mencari informasi. Bahri (2012) mengungkapkan bahwa sebuah perusahaan periklanan di Jepang bernama Dentsu mencoba merumuskan kembali perilaku pembelian seseorang terhadap sebuah produk di era kemajuan internet. Mereka 
merumuskan sebuah model AISAS, dimana attention dan interest yang diberikan oleh slauran-saluran pemasaran melalui sebuah komunikasi pemasarn yang terintegrasi, kemudian pelanggan akan diberikan tempat untuk bisa mencari (search) secara lebih detail dan selanjutnya akan membeli ke tempat-tempat penjualan. Lalu pada akhirnya pelanggan tersebut akan menyebarkan pengalamannya di dunia maya seperti blog dan sosial media.

AISAS menurut Sugiyama dan Andree (2011) adalah proses saat seseorang konsumen memperhatikan produk, layanan, atau iklan (Attention) dan menimbulkan ketertarikan (Interest) sehingga muncul keinginan untuk mengumpulkan informasi (Search) tentang barang tersebut. Pencarian dapat dilakukan di Internet pada blog yang ditulis oleh orang lain, situs produk perbandingan, dan halaman Web resmi perusahaan, atau dengan berbicara dengan keluarga atau teman-teman yang benar-benar telah menggunakan produk atau jasa yang sesuai.

AISAS menurut Puspita (2012) merupakan kepanjangan dari Attention, Interest, Search, Action dan Share. Model ini ditujukan sebagai refleksi atas besarnya pengaruh internet terhadap kehidupan manusia di zaman sekarang. Aktivitas search dan share menjadi kegiatan penting dari pengguna internet. Search dan share merupakan elemen yang transparan, dalam mencari informasi berupa pengalaman pemakai, tingkat pelayanan, kepuasan dan lain-lain. Semuanya langsung dari konsumen bukan dari produsen. Testimonial dan Word of Mouth (WOM) para konsumen menjadi senjata utama.

\section{Literasi Keuangan Syariah}

Loke et al (2005) mengartikan literasi sebagai kemampuan seseorang dalam membaca. Maksud membaca disini bisa diartikan kecakapan dalam menggambarkan idea, menerima dan mengambil makna dari sesuatu simbol melalui daya penglihatan dan/atau sentuhan. Literasi juga melibatkan aktivitas mengarang. Menurut Tompkins (1991) dalam Resmini, literasi merupakan kemampuan menggunakan membaca dan menulis dalam melaksanakan tugas-tugas yang bertalian dengan dunia kerja dan P-ISSN : 2460-9595

E-ISSN : 2686-5149 
kehidupan. Literasi secara luas dimaknai sebagai kemampuan berbahasa yang mencakup kemampuan menyimak, berbicara, membaca dan menulis, serta kemampuan berpikir yang menjadi elemen di dalamnya.

Literasi merujuk pada kompetensi atau kemampuan yang lebih dari sekedar kemampuan baca-tulis. Hanya saja, memang pemahaman yang paling umum mengenai literasi yaitu kemampuan membaca dan menulis. Menurut UNESCO (2006) dalam Buku Indeks Literasi Zakat (2019), pemahaman yang paling umum dari literasi adalah seperangkat keterampilan nyata, khususnya keterampilanZ kognitif membaca dan menulis. Konsep literasi menurut UNISCO terpaku pada tiga hal penting, yakni kemampuan menulis, membaca dan berbicara. Kedua, dilihat dari kemampuan dalam mengartikulasikan angka-angka dan ketiga yakni kemampuan dalam mengakses informasi dan product knowledge tentang hal terkait.

Menurut buku pedoman Strategi Nasional Literasi Keuangan Indonesia (OJK, 2013), yang dimaksud dengan literasi keuangan adalah rangkaian proses atau aktivas untuk meningkatkan pengetahuan (knowledge), Keyakinan (Confidence) dan Keterampilan (Skill) konsumen dan masyarakat luas sehingga mereka mampu mengelola keuangan yang lebih baik. Seseorang dapat dikatakan punya tingkat literasi keuangan yang baik jika memiliki pengetahuan dan keyakinan tentang lembaga, produk dan layanan jasa keuangan, serta keterampilan dalam mengetahui fitur, manfaat, resiko, hak dan kewajiban dari produk dan layanan jasa keuangan tersebut. Sedangkan literasi keuangan menurut Rina (2017) adalah pengetahuan atau pemahaman yang berkaitan dengan pentingnya uang dan kegunaan uang dalam menjawab pertanyaan, mengapa perlunya pengaturan dalam pengeluaran dan pemanfaat uang.

Merujuk pada OJK (2016) untuk Indeks literasi keuangan syariah berdasarkan sektor jasa keuangan terbagi menjadi 6 sektor, yakni Perbankan, Asuransi, Pergadaian, Lembaga Pembiayaan, Pasar Modal dan Dana Pensiun. Adapun untuk mengukur tingkat literasi masyarakat terhadap keuangan syariah dilihat dari pemahaman masyarakat mengenai karakteristik produk dan layanan jasa keuangan syariah yang meliputi: Manfaat, Fitur, Risiko, Biaya, Denda, Cara Memperoleh serta Hak dan Kewajiban sebagai nasabah. 


\section{Metode Penelitian}

Penelitian ini menggunakan data primer dan sekunder. Data sekunder didapatkan melalui kajian literatur tentang gambaran umum tentang strategi marketing dan produk yang di hasilkan melalui buku-buku terkait, jurnal, media massa, internet, dan penelitian terdahulu yang terkait. Untuk data primer dihasilkan melalui kuesioner yang disebar kepada Followers akun instagram perbankan syariah di Indonesian. Jumlah responden dalam penelitian ini adalah 183 responden degan kriteria;

1. Pengguna akun media sosial instagram di Indonesia.

2. Menjadi pengikut (follower) akun instagram perbankan syariah di Indonesia, seperti akun @banksyariahmandiri, @brisyariah, @bank.muamalat dan sejenisnya. Cara pengambilan jumlah sampel dalam penelitian ini mengacu pada teori yang disampaikan oleh Lupiyoadi dan Ridho (2015). Pemilihan jumlah sampel ditentukan dengan menggunakan teknik estimasi dalam perhitungan SEM, yakni maximum likelihood estimation method bahwa jumlah sampel yang dibutuhkan berkisar 100-200 sampel. Berdasarkan ukuran sampel di atas, maka penelitian ini memerlukan 100-200 responden untuk dijadikan sampel penelitian.

Metode yang digunakan dalam penelitian ini adalah Structural Equation Model (SEM). Dalam analisis SEM, tidak ada alat uji statistik tunggal untuk menguji hipotesis mengenai model (Hair et al., 2010). Tetapi berbagai fit index yang digunakan untuk mengukur derajat kesesuaian antara model yang disajikan

Tabel Nilai Goodness of Fit yang dapat diterima

\begin{tabular}{|c|c|c|}
\hline No & Goodness of Fit (GoF) & Cut of Value \\
\hline \multicolumn{2}{|c|}{$\begin{array}{c}\text { Absolute Fit } \\
\text { Measure }\end{array}$} \\
\hline 1 & Root Mean Square Error of Approximation \\
(RMSEA) & $\leq 0.08$ good fit \\
\hline
\end{tabular}




\begin{tabular}{|c|c|c|}
\hline 2 & Root Mean Square Residual (RMR) & $<0,05$ good fit \\
\hline 3 & Goodness of Fit Index (GFI) & GFI $\geq 0,90$ good fit \\
\hline \multicolumn{3}{|c|}{$\begin{array}{c}\text { Incremental Fit } \\
\text { Measure }\end{array}$} \\
\hline 4 & Adjusted Goodness of Fit Index (AGFI) & AGFI $\geq 0,90$ \\
\hline 5 & Comparative Fit Index (CFI) & CFI $\geq 0,90$ good fit \\
\hline 6 & Normed Fit Index (NFI) $\geq 0,90$ good fit \\
\hline 7 & Relative Fit Index (RFI) & RFI $\geq 0,90$ good fit \\
\hline \multicolumn{3}{|c|}{ Parsimonious Fit } \\
Measure
\end{tabular}

\section{Hasil dan Pembahasan}

\section{Uji Kesesuaian model}

Pengujian model SEM bertujuan untuk melihat kesesuaian model. Absolute fit measures adalah ukuran langsung yang digunakan untuk mengetahui seberapa baik model yang ditetapkan dalam penelitian mampu memproduksi data yang diamati. Berdasarkan hasil kesesuaian model, sebuah model yang fit ketika memenuhi indeks pengujian berdasarkan rule of thumb yang disyaratkan. Artinya, model tersebut secara empirik dapat diujikan (terdapat kesesuaian dengan data) yang digunakan dalam studi ini. Ukuran yang digunakan berdasarkan jenis absolute fit measures sebagai berikut:

Tabel Hasil Pengujian Kelayakan Model

\begin{tabular}{|l|c|c|c|}
\hline \multicolumn{1}{|c|}{ Goodness of Fit } & Cut off value & Estimasi & Keterangan \\
\hline$\chi^{2}$-Chi-square $(\mathrm{df}=335)$ & 378.68 & 1305,129 & Buruk \\
\hline CMIN/DF & $\leq 2.00$ & 1,948 & Good fit \\
\hline Probabilitas & $\geq 0.05$ & 0,000 & Buruk \\
\hline RMSEA & $\leq 0.08$ & 0,058 & Good Fit \\
\hline GFI & $\geq 0.90$ & 0,743 & Acceptable \\
\hline AGFI & $\geq 0.90$ & 0,701 & Acceptable \\
\hline TLI & $\geq 0.95$ & 0,902 & Acceptable \\
\hline CFI & $\geq 0.95$ & 0,911 & Accepteble \\
\hline NFI & $\geq 0.90$ & 0,835 & Acceptable \\
\hline
\end{tabular}




\section{Uji Kausalitas}

Hasil output kausalitas model Structural Equation Modeling selengkapnya disajikan pada tabel di bawah ini.

Tabel 4. 1 Regression weight Pengujian Hipotesis Model

\begin{tabular}{|l|r|r|r|r|l|}
\hline \multicolumn{1}{|c|}{ Jalur } & Estimate & S.E. & C.R. & P & Kerangan \\
\hline Interest <-- Attention & 0,848 & 0,067 & 12,734 & 000 & Signifikan \\
\hline Search <--- Interest & 1,117 & 0,085 & 13,185 & 000 & Signifikan \\
\hline Action <--- Search & 0,983 & 0,055 & 17,754 & 000 & Signifikan \\
\hline Share <--- Action & 0,995 & 0,071 & 14,054 & 000 & Signifikan \\
\hline LPS <--- Search & 0,29 & 0,114 & 2,541 & 0,011 & Signifikan \\
\hline LPS <--- Action & 0,143 & 0,052 & 2,729 & 0,006 & Signifikan \\
\hline LPS <--- Share & $-0,1$ & 0,126 & $-0,795$ & 0,426 & Tidak Signifikan \\
\hline
\end{tabular}

Pada tabel di atas menunjukkan bahwa dari 7 hubungan kausalitas yakni Attention ke Interest sebesar 0; interest ke search sebesar 0; search ke action sebesar 0; action ke share ke EC sebesar 0; search ke LPS 0,011; action ke LPS sebesar 0,006 dan share ke LPS sebesar 0,426. Dari tabel di atas terdapat enam hubungan kausalitas yang memiliki hubungan signifikan dan 1 hubungan kausalitas yang tidak signifikan. Hasil selengkapnya disajikan pada penjelasan hiportesis sebagai berikut :

1) Pengujian Hipotesis 1

Hasil pengujian statistik pada hipotesis pertama menunjukkan bahwa nilai parameter estimasi attention terhadap interest sebesar 0 dan nilai CR 12,734. Artinya attention signifikan berpengaruh positif terhadap interest. Berdasarkan hasil tersebut maka dapat disimpulkan bahwa hipotesis pertama yang menyatakan bahwa terdapat pengaruh yang signifikan attention terhadap interest terbukti.

2) Pengujian Hipotesis 2

Hasil pengujian statistik pada hipotesis kedua menunjukkan bahwa nilai parameter estimasi interest terhadap search sebesar 0 dan nilai CR 13,185. Artinya interest signifikan berpengaruh positif terhadap search. Berdasarkan hasil tersebut maka dapat 
disimpulkan bahwa hipotesis kedua yang menyatakan bahwa terdapat pengaruh yang signifikan interest terhadap search terbukti.

3) Pengujian Hipotesis 3

Hasil pengujian statistik pada hipotesis ketiga menunjukkan bahwa nilai parameter estimasi search terhadap action sebesar 0 dan nilai CR 17,754. Artinya search signifikan berpengaruh positif terhadap action. Berdasarkan hasil tersebut maka dapat disimpulkan bahwa hipotesis ketiga yang menyatakan bahwa terdapat pengaruh yang signifikan search terhadap action terbukti.

4) Pengujian Hipotesis 4

Hasil pengujian statistik pada hipotesis keempat menunjukkan bahwa nilai parameter estimasi action terhadap share sebesar 0 dan nilai CR 14,054. Artinya action signifikan berpengaruh positif terhadap share. Berdasarkan hasil tersebut maka dapat disimpulkan bahwa hipotesis keempat yang menyatakan bahwa terdapat pengaruh yang signifikan action terhadap share terbukti.

5) Pengujian Hipotesis 5

Hasil pengujian statistik pada hipotesis kelima menunjukkan bahwa nilai parameter estimasi search terhadap LPS sebesar 0,011 dan nilai CR 2,541. Artinya search signifikan berpengaruh positif terhadap LPS. Berdasarkan hasil tersebut maka dapat disimpulkan bahwa hipotesis kelima yang menyatakan bahwa terdapat pengaruh yang signifikan search terhadap LPS terbukti.

6) Pengujian Hipotesis 6

Hasil pengujian statistik pada hipotesis keenam menunjukkan bahwa nilai parameter estimasi action terhadap LPS sebesar 0,006 dan nilai CR 22,729. Artinya action signifikan berpengaruh positif terhadap LPS. Berdasarkan hasil tersebut maka dapat disimpulkan bahwa hipotesis keenam yang menyatakan bahwa terdapat pengaruh yang signifikan action terhadap LPS terbukti..

7) Pengujian Hipotesis 7

Hasil pengujian statistik pada hipotesis ketujuh menunjukkan bahwa nilai parameter estimasi share terhadap LPS sebesar 0,426 dan nilai CR -0,795. Artinya share signifikan berpengaruh positif terhadap LPS. Berdasarkan hasil tersebut maka P-ISSN : 2460-9595 
46 Joni Iskandar, Mukhammad Najib, Ahmad Mukhlis Yusuf, ANALISIS PENGARUH MODEL AISAS...

dapat disimpulkan bahwa hipotesis ketujuh yang menyatakan bahwa terdapat pengaruh yang signifikan share terhadap LPS tidak terbukti.

Penelitian ini secara keseluruhan menyatakan bahwa instagram mempunyai pengaruh yang efektif untuk menunjang eksistensi perbankan syariah di media sosial. Hal ini ditunjukkan dari hubungan antar variabel yang terdapat pada model AISAS, yakni dari perhatian (attention) secara signifikan mempengaruhi ketertarikan (interest) para pengikut akun bank syariah di instagram. Artinya ketika melihat konten yang diposting oleh akun instagram bank syariah membuat para followers merasa tertarik.

Sedangkan ketertarikan (interest) akan mempengaruhi proses pencarian informasi lebih detail lagi. Hal ini dibuktikan dengan hasil uji hipotesis pada penelitian ini. Para pengikut (followers) yang tertarik dengan dengan konten-konten yang di-upload oleh bank syariah di instagram akan melakukan pencarian mengenai produk, baik dengan menelusuri akun-akun terkait maupun melakukan pencarian di internet. Selanjutnya, dari pencarian menumbuhkan pemahaman serta niatan baru terhadap produk perbankan syariah, sehingga menstimulus para pengikut akun instagram bank syariah untuk membagikan konten dan postingan akun tersebut, semuanya berpengaruh secara berkelanjutan, kebenarannya sudah terkonnfirmasi dengan uji hipotesis yang dilakukan.

Hasil penelitian ini mendukung penelitian sebelumnya yang sudah dilakukan oleh Nurchayati dan Syarif (2018) dengan hasil bahwa AISAS memiliki pengaruh yang baik pada brand image perbankan syariah di instagram. Selanjutnya penelitian ini juga sesuai dengan hasil penelitian Rochman dan Budi (2018) yang menunjukkan bahwa perilaku responden terhadap merek-merek di Instagram memiliki hubungan positif dan memiliki korelasi positif terhadap perilaku responden dengan pendekatan AISAS model. Dari hasil penelitian yang penulis lakukan juga menunjukkan hasil yang sama bahwa sikap para pengikut (followers) terhadap konten-konten bank syariah di Instagram memiliki hubungan positif berdasarkan AISAS model. Penelitian ini juga mengkonfirmasi dari penelitian Abdurrahim et al (2019) bahwa promosi di media sosial memiliki efek yang signifikan terhadap perhatian (Attention), minat (Interest) dan Keinginan (Desire) untuk menemukan informasi lebih lanjut tentang objek yang dipromosiakan. 
Terkait variabel Literasi Perbankan Syariah (LPS), Otoritas Jasa Keuangan sudah memasukkan internet sebagai salah satu saluran strategi yang bisa digunakan untuk meningkatkan pemahaman masyarakat terhadap edukasi produk keuangan syariah (2016). Dua dari tiga variabel pada model AISAS yang diajukan sebagai hipotesis yang berpengaruh terhadap LPS pada penelitian ini menunjukkan pengaruh yang positif terhadap peningkatan literasi masyarakat terhadap perbankan syariah. Dua variabel tersebut yakni proses pencarian informasi (search) dan tindakan para followers akun bank syariah (action). Artinya, aktivitas mencari informasi yang dilakukan para pengguna instagram setelah memperhatikan konten perbankan syariah membuat mereka untuk mempelajari lebih lanjut informasi yang didapatkan, sehingga secara tidak langsung meningkatkan pemahaman mereka terhadap produk dan informasi mengenai bank syariah. Selanjutnya, proses penelusuran infomasi tersebut turut mempengaruhi tindakan para pengguna instagram terhadap perbankan syariah, yang pada akhirnya juga menstimulus tingkat literasi mereka terhadap perbankan syariah.

Sementara variabel yang tidak memiliki pengaruh signifikan dalam peningkatan literasi perbankan syariah adalah proses berbagi pemahaman dan pengalaman (share). Hal ini disebabkan karena aktivitas sharing adalah kegiatan yang dilakukan para pengguna instagram dengan tujuan untuk memberi tahu teman atau orang-orang yang mengikutinya di instagram. Dengan kata lain, informasi mengenai produk perbankan syariah yang mereka bagikan ditujukan untuk pihak ketiga yang bukan termasuk pada cakupan penelitian ini. Untuk mengukurnya, perlu penelitian khusus yang lebih spesifik.

Rina (2017) mengungkapkan bahwa proses edukasi literasi keuangan pada masyarakat bisa melalui pendidikan formal maupun non formal, baik secara langsung maupun tidak langsung. Media sosial dalam hal ini instagram merupakan alternatif model edukasi kekinian yang hadir sebagai bentuk tuntutan zaman, sifatnya interaksi dua arah dalam bentuk pendekatan strategi non formal. Sementara Isnurhadi (2013) menyebutkan bahwa ada dua variabel yang dapat mempengaruhi literasi masyarakat terhadap perbankan syariah, yaitu pengetahuan individu terhadap muamalah dalam Islam serta variabel upaya promosi yang dilakukan oleh perbankan syariah. Keberadaan bank syariah di instagram yang aktif memproduksi konten-konten bank syariah P-ISSN : 2460-9595 
merupakan bentuk bentuk promosi dan edukasi yang berpengaruh positif terhadap tingkat literasi masyarakat terhadap perbankan syariah.

\section{Simpulan}

Dari hasil pengujian yang telah dilakukan terhadap permasalahan yang dirumuskan dalam hipotesis penelitian dengan menggunakan uji kausalitas, maka dapat ditarik kesimpulan sebagai berikut:

1. Variabel attention memiliki pengaruh yang signifikan dan bernilai positif terhadap variabel dependen, yaitu interest.

2. Variabel interest memiliki pengaruh yang signifikan dan bernilai positif terhadap variabel dependen, yaitu search.

3. Variabel search memiliki pengaruh yang signifikan dan bernilai positif terhadap variabel dependen, yaitu action.

4. Variabel action memiliki pengaruh yang signifikan dan bernilai positif terhadap variabel dependen, yaitu share.

5. Variabel search memiliki pengaruh yang signifikan dan bernilai positif terhadap variabel dependen, yaitu Literasi Perbankan Syariah.

6. Variabel action memiliki pengaruh yang signifikan dan bernilai positif terhadap variabel dependen, yaitu Literasi Perbankan Syariah.

7. Variabel share tidak memiliki pengaruh yang signifikan walaupun bernilai positif terhadap variabel dependen, yaitu Literasi Perbankan Syariah.

Berdasarkan hasil penelitian yang telah dilakukan, terdapat beberapa saran yang perlu disampaikan pada pihak yang bersangkutan dan bahan pertimbangan untuk penelitian selanjutnya, yaitu sebagai berikut:

1. Penelitian ini hanya menganalisis perilaku pengguna internet pada platform 
instagram saja. Untuk penelitian selanjutnya bisa dikembangkan ke media sosial yang lain seperti twitter, facebook, youtube dan juga website yang digunakan perbankan atau situs yang secara khusus memberikan edukasi tentang keuangan syariah, seperti MySharing, Muamala.net dan sejenisnya.

2. Penelitian hanya menganalisis tingkat literasi keuangan masyarakat hanya pada sektor perbankan saja. Untuk penelitian selanjutnya bisa dikembangkan pada lima sektor keuangan lainnya, yakni sektor lembaga pembiayaan, pegadaian, asuransi, pasar modal dan dana pension. Lebih ideal lagi jika menganalisis keenam sektor keuangan yang telah disusun oleh Otoritas Jasa Keuangan (OJK) secara bersamaan.

3. Lembaga perbankan syariah di Indonesia musti memaksimalisasi tehnik digital marketing dalam penggunaan sosial media, khususnya instagram. Adapun tehnik yang perlu digunakan seperti penulisan caption dengan tehnik copywriting, riset hastage agar bisa menjangkau pengguna internet lebih banyak lagi dan menempatkan secara khusus tim analisis maupun admin yang me-maintenance semua saluran informasi kantor perbankan.

\section{DAFTAR PUSTAKA}

Abdurrahim, M.S, et al. (2019). Development of AISAS Model to See the Effect of Tourism Destination in Social Media. Journal of Applied Management (JAM), Bol. 17, No.1, pp: 133-143.

Akinola, O.O, \& Deborah, O.O. (2015). Evaluating The Use of Internetas a Medium for Marketing and Advertising Messages in Nigeria. African Journal of Marketing Management. Vol. 8 (2), pp: 40-63.

Asosiasi Penyeleneggara Jasa Internet Indonesia. Penetrasi \& Perilaku Pengguna Internet Indonesia. Survei 2016.

Asosiasi Penyeleneggara Jasa Internet Indonesia. Penetrasi \& Profil Perilaku Pengguna Internet Indonesia. Survei 2018.

Asyraf, W.M. (2013). A Comparison Of Partial Least Square Structural Equation Modeling (PLS-SEM) and Covariance Based Structural Equation Modeling (CB- 
SEM) for Confirmatory Factor Analysis. International Journal of Engineering Science and Innovative Technology (IJESIT) Vol. 2, pp: 120-131.

Bank Indonesia. Cetak Biru Pengembangan Perbankan Syariah di Indonesia Periode 2002- 2011.

Bahri, Rayza Ardian. (2012). Analisi Pengaruh Endorser di Sosial Media Terhadap Pengambilan Keputusan Pembelian Produk dengan Metode AISAS. Tesis Universitas Indonesia. Jakarta.

Charisma, Silvia Dwi. (2014). Penggunaan Media Sosial Sebagai Sarana Komunikasi Bagi Komunitas. Skripsi, Universitas Pembangunan Nasional "Veteran" Jawa Timur.

Ferdianto, Hengki. (2010). 111 Cara Menghasilkan Uang dengan Blog. Yogyakarta: CV Andi OFFSET.

Ferdinand, A. (2002). Structural Equation Modelling dalam Penelitian Manajemen. Semarang: Undip.

Gharibi, Sahar et al. (2012). Explain the Effectiveness of Advertising Using AIDA Model. Institute of Interdisciplinary Business research, Islamic Azar University, Iran. Vol. 4(2), pp: 333-345.

Ghutrie, John T et al. (2006). Influences of Stimulating Tasks on Reading Motivation and Comprehension. The Journal of Educational Research. Maret Vol. 99(4), pp: 85- 100 .

Ghozali, Imam. (2006). Aplikasi Analisis Multivariate dengan Program SPSS. Universitas Diponogoro. Semarang.

Hair, et al. (1998). Multivariate Data Analysis. 7Th edition. New Jersey: Prentice. Haryono, Siswoyo \& Wardoyo, Parwoto. (2012). Structural Equation Modelling untuk Penelitian Manajemen Menggunakan AMOS 18. PT. Intermedia Personalia Utama: Jawa Barat.

Hardianti, Fitri. (2019). Representasi Diri Social Climber (Studi Pada Pengguna Media Sosial Instagram). Bandung: Penerbit Aksel Media Akselerasi: Universitas Padjadjaran.

Hereyah, Yoyoh. (2014). Iklan Mobil Media Cetak: Analisis Elemen Copywriting dan Viasualisasi di Majalah SWA. Jurnal Visi Komunikasi Volume 13, No.02, November, pp: 1-12.

Hermawan, Dr. Asep, M.Sc. 2005. Penelitian Bisnis Paradigma Kuantitatif. Jakarta: PT Grasindo.

Ikit. (2015). Akuntansi Perhimpunan Dana Perbankan Syariah. Yogyakarta: Deepublish Publisher. 
Indrawati et al. (2019). Marketing for Non-Marketing Superintendents. Jakarta: Gramedia.

Isnurhadi. (2013). Kajian tingkat literasi masyarakat terhadap perbankan syariah: Studi kasus masyarakat kota palembang. Laporan Hasil Penelitian.

Hambali, M.Y. (2018). Pengaruh Literasi Keuangan Syariah terhadap Perilaku Keuangan Masyarakat Sekitar Pondok Pesantren di Kecamatan Cibitung Bekasi. Intitut Pertanian Bogor, Bogor.

Hamzani, Achmad Irwan, Aravik, Havis, Khasanah, Nur, (2018). Paradigm Modernism Islam in Reiterpretation of Islamic Law in the Millennial Era, International Conference on Islam and Muslim Societies (ICONIS), Agustus 2018.

Joreskob, K. G \& Sorbom, D. (1987). New Development in LISREL., Paper presented at the National Syposium on Methodological Issues in Casual Modeling. Tuscalosa: University of Alabama.

Jubilee. (2012). Instagram Untuk Fotografi Digital dan Bisnis Kreatif. Jakarta: Penerbit PT Elex Media Komputindo.

Loke, Siow Heng et al. (2005). Pedagogi Meretas Kurikulum. Pahang Malaysia: PTS Professional Publishing.

Lopiyoadi, Rambat \& Ridho B.A. (2015). Praktikum Metode Riset Bisnis. Penerbit Salemba Empat: Jakarta Selatan.

Margono. (2004). Metodologi Penelitian Pendidikan. Jakarta : Rineka Cipta.

Meilyana, Elizabeth. (2018). AISAS (Attention, Interest, Search, Action, Share) Model. (Online), (http://bbs.binus.ac.id/international-marketing/2018/08/aisas-model/).

Muljono, R.K. (2018). Digital Marketing Concept: Penggunaan Konsep Dasar Digital Marketing untuk Membuat Perubahan Besar. Jakarta: PT Gramedia.

Nurchayati, Umi \& Syarif As'ad. (2018). Consumer Responses Analysis of Digital Marketing Strategies in Islamic Banks to Enhance the Consumer-Brand Relationship Quality. Universitas Muhammadiyah Yogyakarta, BantulYogyakarta, hal : 1-19.

Otoritas Jasa Keuangan. (2016). Statistik Perbankan Syariah Desember - Vol. 15, No 1. 2016

Otoritas Jasa Keuangan. (2018). Statistik Perbankan Indonesia. Desember 2018 Otoritas Jasa Keuangan. (2019). Statistik Perbankan Indonesia. Januari 2019

Otoritas Jasa Keuangan. (2015). Siaran Pers Gelar Pasar Keuangan Rakyat di Medan. Nomor: SP-84/DKNS/OJK/10/2015.

Otoritas Jasa Keuangan. (2016). Hasil Survei Nasional Literasi dan Inklusi Keuangan 2016. 
Otoritas Jasa Keuangan. (2013). Strategi Nasional Literasi Keuangan Indonesia 2013. Pusat Kajian Strategi Badan amil Zakat Nasional. Indeks Literasi Zakat: Teori dan Konsep. 2019.

Puspita, R.A. (2012). Rancangan Program Kampanye Komunikasi Pemasaran dengan Konsep AISAS. Universitas Indonesia. Jakarta.

Rahman, Aulia. Analisis Faktor - Faktor Yang Mempengaruhi Market Share Bank Syariah. Jurnal Analytica Islamica, Vol. 5, No. 2. 2016, pp: 890-900.

Rahmawaty, Anita. Pengaruh Persepsi Tentang Bank Syariah Terhadap Minat Menggunakan Produk di BNI Syariah Semarang. Addin, Vol. 8, No. I, Februari 2014, pp: 25-40.

Resmini, Novi. Tanpa Tahun. Orasi dan Literasi dalam Pengajaran Bahasa. Universitas Pendidikan Indonesia.

Rina, Lelahester. (2017). Upaya Peningkatan Literasi Keuangan Melalui Pendidikan Keuangan Dalam Menciptakan Perilaku Menabung di Kalangan Mahasiswa. Sumber dari situs https://www.researchgate.net/publication/331992613.

Rochman, A.A, \& Budi P.I. (2015). Users' Engagement Toward The Brand Accounts in Instagram Based on The AISAS Model. Journal of Business and Management, Vol. 4, No. 8. Institut Teknologi Bandung, Indonesia.

Santoso. (2010). Statistik Multivariat, Konsep dan Aplikasi dengan SPSS. Elex Media Komputindo : Jakarta

Sholeh, Maimun \& Rahmawati Deylla Handika. (2018). Pengaruh Tingkat Pengetahuan, Kualitas Layanan, dan Tingkat Literasi Keuangan Syariah Terhadap Pengambilan Keputusan Masyarakat Muslim Menggunakan Produk Perbankan Syariah di Daerah Istimewa Yogyakarta. Jurnal Economia, Vol 14, No 1.

Sulastyawati, Dwi, Aravik, Havis, Yunus, Nur Rohim, (2019). The Existence of Tax as an Instrument of the State Revenue in the Perspectives of Islamic Law and Economics, Research and Analysis Journal, Vol. 2, No. 11.

Sunyoto, Danang. (2012). Konsep Dasar Riset Pemasaran dan Perilaku Konsumen. PT Buku Seru. Jakarta.

Sugiyono. (2011). Metode Penelitian Kuantitatif, Kualitatif dan R\&D. Penerbit Alfabeta. Bandung.

Sugiyama, Kataro dan Andree. (2011). The Dentsu Way: Secrets of Cross Switch Marketing from the World's Most Innovative Advertising. New York, United State, McGraw Hill Profesional.

Suyatno et al, (2007). Kelembagaan Perbankan. Jakarta: PT Gramedia Pustaka Utama. Syafii, M.A. (2001). Bank Syariah dari Teori ke Praktik. Jakarta: Gema Insani 
Tohirudin, Muhammad. (2012). Membuat Situs Top Search Mahir SEO untuk Pemula. Depok: Kanaya Press.

Willya, Rumondor dan Busran. (2018). Senarai Penelitian: Islam Kontemporer Tinjauan Multikultural. Sleman Yogyakarta Deepublish Group Penerbitan CV Budi Utama. Wirianti, Ferlina \& Effy Z.R. (2017). Electronic Word of Mouth Communication Analysis on Visitation Decision Making Process Using AISAS Model on Instagram Users:

Study on Visit Decision to Japan. Indo-IGCC Proceeding, Universitas Indonesia, hal: 679-699.

Wiwoho, Jamal. Peran Lembaga Keuangan Bank dan Lembaga Keuangan Bukan Bank Dalam Memberikan Distribusi Keadilan Bagi Masyarakat. MMH, Jilid 43 No.1 Januari 2014.

Yuliani, Nana. (2016). Pertumbuhan Perbankan Syariah di Indonesia. Tesis, Universitas Islam Negeri (UIN). Yogyakarta. 